Article

\title{
Evaluation of High-Speed Railway Bridges Based on a Nondestructive Monitoring System
}

\author{
Mosbeh R. Kaloop ${ }^{1,2}$, Jong Wan Hu ${ }^{1,3, *}$ and Emad Elbeltagi ${ }^{4}$ \\ Received: 14 October 2015; Accepted: 11 January 2016; Published: 18 January 2016 \\ Academic Editor: César M. A. Vasques \\ 1 Department of Civil and Environmental Engineering, Incheon National University, Incheon 406-840, \\ Korea; mosbeh.kaloop@gmail.com \\ 2 Public Works and Civil Engineering Department, Mansoura University, Mansoura 35516, Egypt \\ 3 Incheon Disaster Prevention Research Center, Incheon National University, Incheon 406-840, Korea \\ 4 Structural Engineering Department, Mansoura University, Mansoura 35516, Egypt; eelbelta@mans.edu.eg \\ * Correspondence: jongp24@incheon.ac.kr; Tel.: +0082-32-835-8463
}

\begin{abstract}
Recently, trains' velocities in Korea increased more than the speed used in the design of some bridges. Accordingly, this paper demonstrates the evaluation of a railway bridge due to high-speed trains' movement. A nondestructive monitoring system is used to assess the bridge performance under train speeds of 290,360, 400 and $406 \mathrm{~km} / \mathrm{h}$. This system is comprised of a wireless short-term acceleration system and strain monitoring sensors attached to the bridge girder. The results of the analytical methods in time and frequency domains are presented. The following conclusions are obtained: the cross-correlation models for accelerations and strain measurements are effective to predict the performance of the bridge; the static behavior is increased with train speed developments; and the vibration, torsion, fatigue and frequency contents analyses of the bridge show that the bridge is safe under applied trains' speeds.
\end{abstract}

Keywords: high-speed; bridge; strain; monitoring; prediction

\section{Introduction}

Nowadays, transportation by high-speed trains is considered as one of the important transportation facilities in South Korea as well as in the world's high income countries.Therefore, increasing of the trains' speed is one of the main problems facing existing infrastructure facilities. In Korea, high speed trains startedin 1992 from Seoul to Busan, while the Korea Train eXpress (KTX) services were launched on 1 April 2004.The bridges and infrastructure of express trains have been developing continuously from 1970. Most high-speed railway bridges are designed based on $350 \mathrm{~km} / \mathrm{h}$ velocity. Therefore,with the velocity increase, existing bridges should be redesigned and evaluated. The newly-completed train HEMU-430X is currently running at high speed over $400 \mathrm{~km} / \mathrm{h}$ in the transportation network of Korea. Therefore, this study aims to evaluate the existing composite steel Kaya Bridge of Seoul-Busan High-Speed Railway under the effect of the high speed train movement. The acceleration and strain measurements are used to evaluate the composite bridge under velocities between 290 to $406 \mathrm{~km} / \mathrm{h}$.

Lee et al. [1] evaluated steel and pre-stressed concrete (PC) box girder bridgesunder high speed trains up to $289.3 \mathrm{~km} / \mathrm{h}$. From their study, they found that no noticeable differences of dynamic responses due to the different materials (steel or concrete) could be found. Xia et al. [2] evaluated the real observation for the multi-span PC of high-speed railway bridges in a time domain. In their study, they recommended the use of the results as a reference for the design of high-speed railway bridges. Ding et al. [3] used the long term acceleration measurements to evaluate high-speed railway steel bridges. More monitoring systems for the effect of high-speed railway trains on bridges can 
be found in [4-7]. In general, the main objective of the structural health monitoring (SHM) systems is collecting the observations or information to detect and assess bridge condition, damage, fatigue and performance for proper and timely maintenance intervention. In order to identify the modes of bridge characteristics, it is necessary to excite the structure in order to produce a response at each relevant mode. The loads and response of structures are parameters for the monitoring of the bridge performance under current and future loadings conditions. Typical SHM implementations in highway and steel bridges are summarized in [8,9]. In addition, for continuous health monitoring studies, the response monitoring technique is more suitable [10].

The evaluation methodologies of high speed railway bridges are concluded in [11-13]. Sartos et al. [14] assessed the stress/strain levels, load distributions, and fatigue for four different bridges based on strain measurements, and they concluded that the system is effective in the static performance analysis. Xia et al. [15] used asimulation model to evaluate vertical and lateral bridge behavior under high-speed trains. The results of their study showed that the deflections and accelerations of the bridge girder are in accordance with the safety and comfort standards of bridges and running train vehicles. Ding et al. [3] proposed the parametric (polynomial fitting) and nonparametric (correlation models, mean value control, root mean square (RMS)) statistical methodology for the acceleration measurements to study the safety and early-warning of the bridge. From their study, they found that the quadratic polynomial fitting provides a good capability for detecting the abnormal changes of the transverse acceleration measurements. Furthermore, the correlation models describing the overall structural behavior of the bridge can be obtained with the support of the health monitoring system, which includes cross-correlation models for accelerations. Liu et al. [6] concluded that the numerical simulation gives a good relation between the predicted and the measured responses. Therefore, the statistical analysis can be used to detect fatigue, torsion and reliability of structures based on strain and displacement measurements [16-18]. Furthermore, parametric models are used to detect the performance of structures based on acceleration and strain measurements $[19,20]$. The main advantage of these methods is the ability to use them to evaluate and detect structural movements and damage.

The proposed study aims to evaluate Kaya bridge performance using a nondestructive monitoring system designed to assess the existing bridge under high-speed train movement as well as investigating the bridge structural behavior based on a simple application of time series and frequency analyses for the acceleration and strain responses. Finally, the effectiveness of the monitoring sensors in time and frequency domains is assessed in order to decrease the monitoring system cost.

\section{Kaya Bridge, High-Speed Trainsand Monitoring System Descriptions}

Kaya Bridge, shown in Figure 1a, is a composite steel box girder bridge with $50 \mathrm{~m}$ span supports two line high-speed railways. The cross-section of the bridge is shown in Figure 1b. Two longitudinal girders are used with a spacing of $6.5 \mathrm{~m}$ and reinforced concrete deck with $14.00 \mathrm{~m}$ wide, which is used to provide the large stiffness for such heavy live loads. The use of a steel box as the deck system is another feature in the design of this bridge, which is adopted to reduce uneven deflection and torsion of the deck. The bridge design criteria at the mid span are presented in Table 1.

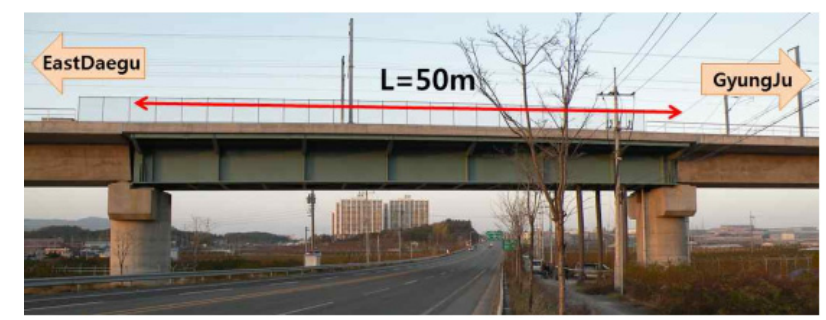

(a)

Figure 1. Cont. 


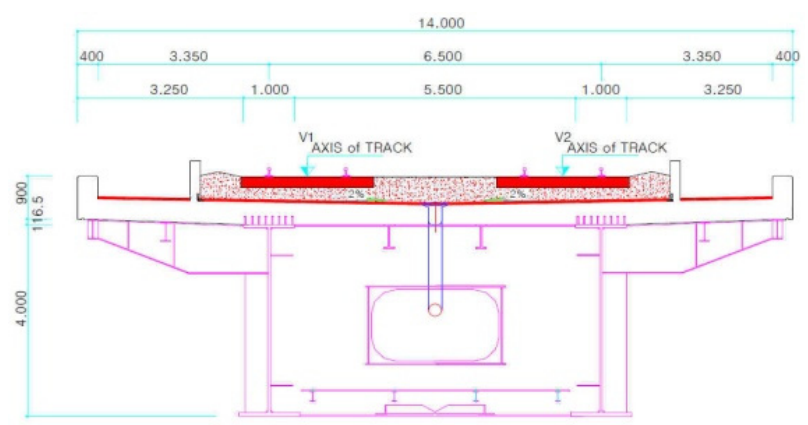

(b)

Figure 1. Kaya bridge (a) view and (b) cross section (dimensions in $\mathrm{mm}$ ).

Table 1. Railway Bridge design criteria [5].

\begin{tabular}{ccc}
\hline Review Factor & Criteria & Note \\
\hline Vertical acceleration & $4.9 \mathrm{~m} / \mathrm{s}^{2}$ & For concrete track \\
Displacement as safety & $82 \mathrm{~mm}$ & Under $350 \mathrm{~km} / \mathrm{h}$ \\
Displacement as comfort & $22 \mathrm{~mm}$ & Under $350 \mathrm{~km} / \mathrm{h}$ \\
Track twist & $0.4 \mathrm{~mm} / \mathrm{m}$ & By dynamic analysis \\
\hline
\end{tabular}

The next-generation high-speed developed train (HEMU-430X) is intended to travel with a maximum speed of $430 \mathrm{~km} / \mathrm{h}$ (Figure 2). The high-speed train is controlled to pass over the bridge in the passage track with four different speeds, i.e., $290,360,400$, and $406 \mathrm{~km} / \mathrm{h}$.

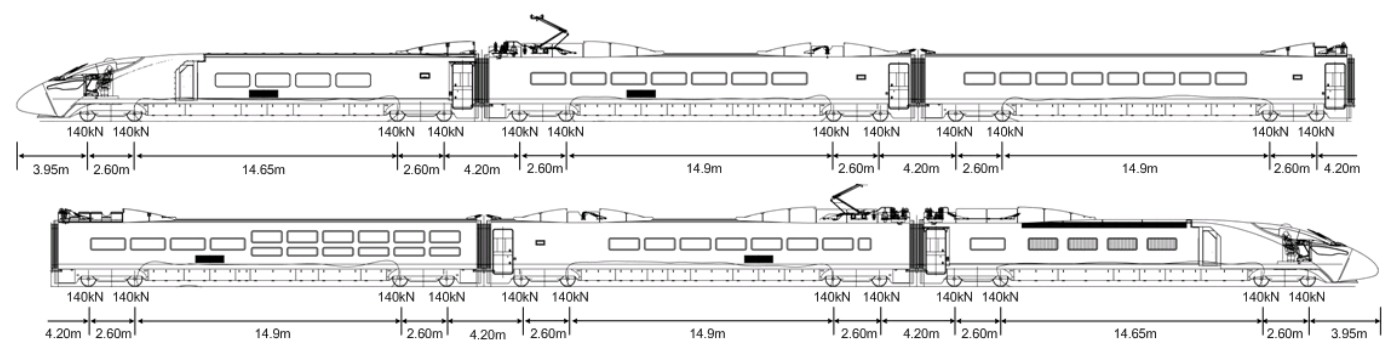

Figure 2. Axial spacing and loading of the high-speed train.

To monitor the behavior of the bridge as per the passing of the high speed trains, a wireless SHM system was designed and installed on the Kaya Bridge shortly after it was opened to use the HEMU-430X train, as shown in Figure 3. This on-line concise SHM system was designed with a minimum of 20 sensors to monitor the key parameters. Moreover, a total of 20 accelerometer and strain gauge sensors (five sensors on each railway track) with sampling frequency of $100 \mathrm{~Hz}$ were installed on the main girders under each railway track in each direction with equal-spacing of $8.3 \mathrm{~m}$. The sensors were installed at the bottom flange of the main girders in the vertical direction to detect and monitor the vertical vibration and fatigue of the bridge, as illustrated in Figure 3. The entire system consists of a set of sensors, data acquisition, data transmission, data management and a structural evaluation mechanism. The primary purpose of the system is to monitor in-service performance of the bridge structure under high-speed trains, and to provide early warning of abnormal changes in in-service performance of the bridge. Herein, the structural parameters to be monitored in the Kaya Bridge were determined using the structural sensitivity analysis with the finite element model under the designed train speeds action, as shown in Kim et al. [5]. Other important parameters including accelerations, strains, deformations and fatigue of the steel box girder bridge were monitored and studied under different speeds of the passing high-speed trains. 


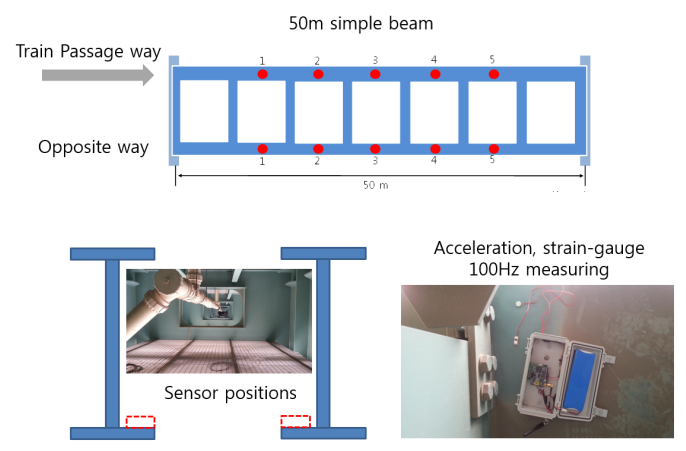

Figure 3. Structural health monitoring (SHM) system locations and components.

\section{Evaluation of the Bridge Condition Using SHM Monitoring Data}

Kim et al. [5] designed a 3-D finite element model (FEM) of the Kaya Bridge using ANSYS V10.0 software (ANSYS, Canonsburg, PA, USA, 2005) to support the proposed movement analysis of different train's speeds. Train speeds from 200 to $450 \mathrm{~km} / \mathrm{h}$ were studied. The FEM model results are concluded as follows: (i) the natural frequency modes of the bridge are 3.186 (1st bending), 3.689 (2nd bending) and 5.913 (1st torsion) $\mathrm{Hz}$ for the first, second and third modes, respectively; (ii) the maximum vertical acceleration and displacement are $3.5 \mathrm{~m} / \mathrm{s}^{2}$ and $6 \mathrm{~mm}$ occurred with train speed 250 and $280 \mathrm{~km} / \mathrm{h}$, respectively; (iii) the maximum acceleration and displacement for the train $400 \mathrm{~km} / \mathrm{h}$ speed are $1.6 \mathrm{~m} / \mathrm{s}^{2}$ and $3.8 \mathrm{~mm}$, respectively. Therefore, comparing the FEM results and the bridge design criteria in Table 1 shows that the bridge is safe under applied loads.

The current study utilizes the real monitoring data that is collected from the SHM system of Kaya Bridge to assess and evaluate the real bridge condition in terms of its vibration, static strain, torsional and fatigue behavior of the steel deck as well as evaluating and comparing the frequency contents for the measurements of the monitoring sensors.

\subsection{Evaluation of the Bridge Girder Vibration Behavior}

Figure $4 \mathrm{a}, \mathrm{b}$ illustrate the typical vertical acceleration time histories of the passage monitoring points of the girder measured from accelerometers 1 to 5 for the $290 \mathrm{~km} / \mathrm{h}$ and $406 \mathrm{~km} / \mathrm{h}$ speed, respectively. It can be seen that the $d t,\left(d t=t_{2}\right.$ (leave time) $-t_{1}$ (entrance time)) values are reported as $5.9,2.92,1.9$ and $1.85 \mathrm{~s}$ with the speeds $290,360,400$ and $406 \mathrm{~km} / \mathrm{h}$, respectively. This means that the vibration time effect on the bridge decreased by $68.65 \%$ as the train speed increased from 290 to $406 \mathrm{~km} / \mathrm{h}$. In addition, it is observed that the vibrations of the monitored points at a speed of $290 \mathrm{~km} / \mathrm{h}$ are approximately the same, while as the speed increased, the entrance and exit monitoring points are experiencing high vibration response compared to the mid span point.

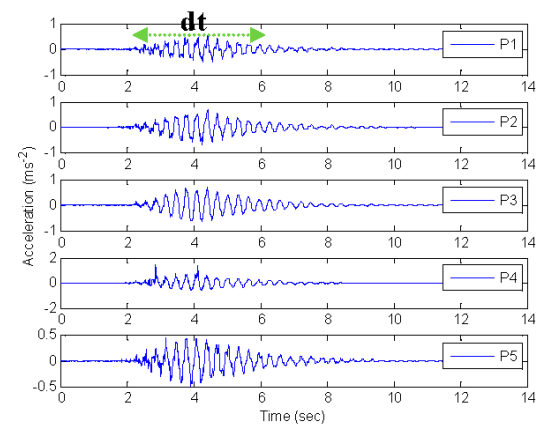

(a)

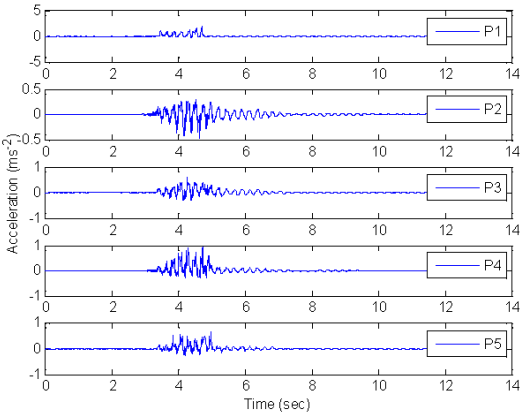

(b)

Figure 4. Vertical acceleration time histories of the girder caused by a high-speed train. (a) passage response points for $290 \mathrm{~km} / \mathrm{h}$; (b) passage response points for $406 \mathrm{~km} / \mathrm{h}$. 
Figure 5 shows that the vertical acceleration of the mid-span point of the girder at $406 \mathrm{~km} / \mathrm{h}$ is much smaller than that of $290 \mathrm{~km} / \mathrm{h}$. In addition, it is noticed that the vibration response for the passage way is higher than that of the opposite side at 400 and $406 \mathrm{~km} / \mathrm{h}$, while at 290 and $360 \mathrm{~km} / \mathrm{h}$, the acceleration responses for the passage and opposite sides are equal. These indicate that, although the structural layouts of the five monitoring points of the main girder are the same, there is a significant difference between the vertical vibration characteristics of two sides of the bridge due to the rail irregularity in the vertical directions with different speeds. Thus, there is a need to monitor the vertical accelerations of the span in the long term so as to realize anomaly alarms for vibration behavior of the main girder.In addition, the measured vertical acceleration is smaller than the FEM results by $62 \%$ according to the design criteria of the bridge (as shown Table 1), which means that the real response is safe. Furthermore, the girder torsional behavior should be studied with new development trains' speeds.

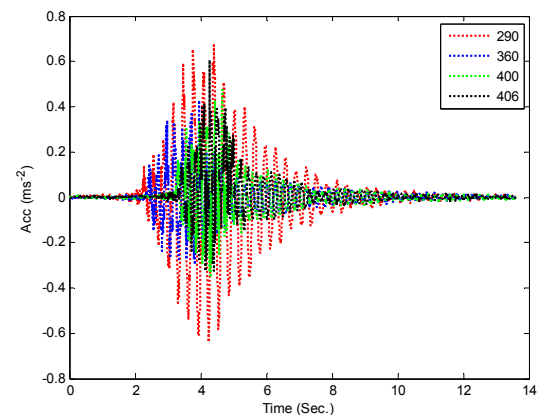

(a)

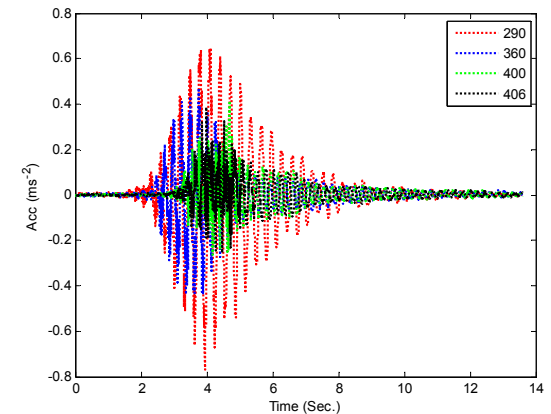

(b)

Figure 5. Vertical acceleration time histories of the passage and opposite mid span girder point. (a) passage response of mid span point; (b) opposite response of mid span point.

Figure 6 illustrates the dynamic torsional behavior of the bridge girder based on vertical acceleration measurements [21].The torsional behavior of the girder due to train passage at $406 \mathrm{~km} / \mathrm{h}$ is shown in Figure 6a. While the torsional behavior of the mid span point at different speeds is shown in Figure 6b.

$$
\mathrm{T}=\frac{\mathrm{a}_{\text {pass }}-\mathrm{a}_{\mathrm{opps}}}{l}
$$

where $\mathrm{T}, \mathrm{a}_{\text {pass }}, \mathrm{a}_{\mathrm{opps}}$ and $l$ are the torsion, acceleration for the passage and opposite points and distances between sensors' positions.

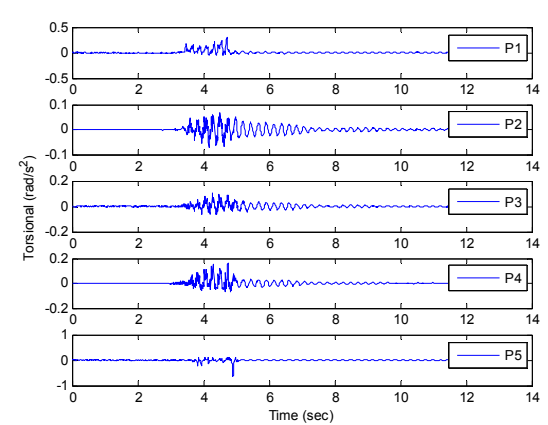

(a)

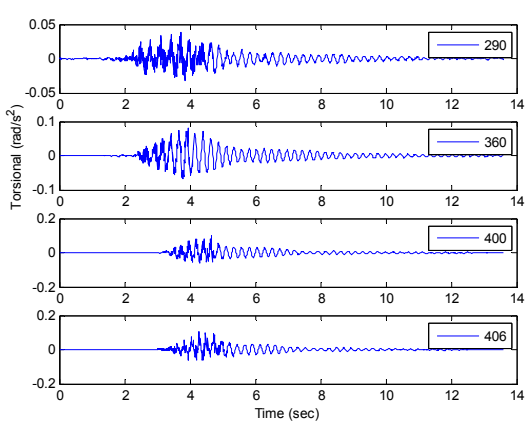

(b)

Figure 6. Torsional measurements for the bridge girder. (a) the torsional of the monitoring points at $406 \mathrm{~km} / \mathrm{h}$ passage; (b) mid span point torsional values.

It is noticed that the torsional values increased as the train velocity increased with maximum values at points 1 and 5 . As the speed increased from 290 to $406 \mathrm{~km} / \mathrm{h}$, the torsional values increased by 
$61.20 \%$, while they increased by $22.33 \%$ as the train speed increased from 360 to $406 \mathrm{~km} / \mathrm{h}$. This means that the bridge deck torsional response is higher than the vibration response. The girder torsional value at the mid span point, $0.103 \mathrm{rad} / \mathrm{s}^{2}$, is within the design values, as shown in Table 1 .

The statistical parameters, maximum and root mean square (RMS), for the acceleration measurements and torsional calculations at 360 and $406 \mathrm{~km} / \mathrm{h}$ are presented in Table 2 . The $360 \mathrm{~km} / \mathrm{h}$ is assumed as the base-speed for the study of the bridge safety because the bridge design speed is $350 \mathrm{~km} / \mathrm{h}$. Furthermore, the Bessel filter cut-off frequency of $30 \mathrm{~Hz}$ is applied to remove the noise measurements of the accelerometer [21]. It is noticed that the maximum acceleration occurred at points 1 and 5 for the passage and opposite directions at $406 \mathrm{~km} / \mathrm{h}$ speed, respectively, with values within the design limits as shown in Table 1. While there is no high relative change at points 2 to 4 , the RMS of the $360 \mathrm{~km} / \mathrm{h}$ is smaller than that of the $406 \mathrm{~km} / \mathrm{h}$ on passage way, while vice versa in the opposite way except for point 5 . The maximum torsion occurred at point 5 at a speed of $406 \mathrm{~km} / \mathrm{h}$ with a value very close to the design value (Table 1). Thus, it is recommended to limit the train speed to $400 \mathrm{~km} / \mathrm{h}$ only. In addition, the effective torsion test should be assessed at the end points of the bridge (point of maximum torsion).

Table 2. Maximum acceleration, root mean square (RMS) and torsional acceleration for the filtration of vibration measurements.

\begin{tabular}{|c|c|c|c|c|c|c|c|c|c|c|}
\hline \multirow{3}{*}{ Point } & \multicolumn{4}{|c|}{ Acceleration $\left(\mathrm{m} / \mathrm{s}^{2}\right)$} & \multicolumn{4}{|c|}{ RMS (m/s $\left.\mathrm{s}^{2}\right)$} & \multirow{2}{*}{\multicolumn{2}{|c|}{$\begin{array}{l}\text { Max Torsion } \\
\quad\left(\mathrm{rad} / \mathrm{s}^{2}\right)\end{array}$}} \\
\hline & \multicolumn{2}{|c|}{ Passage } & \multicolumn{2}{|c|}{ Opposite } & \multicolumn{2}{|c|}{ Passage } & \multicolumn{2}{|c|}{ Opposite } & & \\
\hline & 360 & 406 & 360 & 406 & 360 & 406 & 360 & 406 & 360 & 406 \\
\hline 1 & 0.104 & 1.251 & 0.196 & 0.079 & 0.006 & 0.035 & 0.008 & 0.004 & 0.059 & 0.191 \\
\hline 2 & 0.169 & 0.183 & 0.231 & 0.088 & 0.008 & 0.009 & 0.011 & 0.006 & 0.072 & 0.191 \\
\hline 3 & 0.244 & 0.319 & 0.279 & 0.146 & 0.010 & 0.012 & 0.013 & 0.007 & 0.079 & 0.037 \\
\hline 4 & 0.569 & 0.622 & 0.252 & 0.239 & 0.014 & 0.016 & 0.012 & 0.008 & 0.244 & 0.055 \\
\hline 5 & - & 0.401 & 0.169 & 2.497 & - & 0.013 & 0.008 & 0.035 & - & 0.343 \\
\hline
\end{tabular}

Ding et al. $[3,17]$ concluded that the quadratic linear fitting for the maximum and RMS are calculated for the acceleration measurements can be used to detect the performance of high-speed railway bridges based on one span monitoring. Herein, this method is applied to detect and check the performance of the bridge due to different speeds on the two ways of the track. The maximum and RMS of 150 acceleration of the original measurements are shown in Figure 7. The quadratic linear fitting is suitable for the maximum acceleration (Figure 7a), while the RMS shows no correlation between the passage and opposite ways. Therefore, the maximum acceleration fitting can be used to check the safety of the bridge.

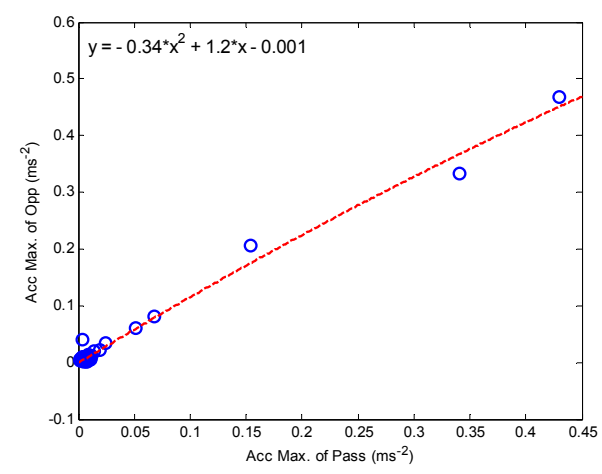

(a)

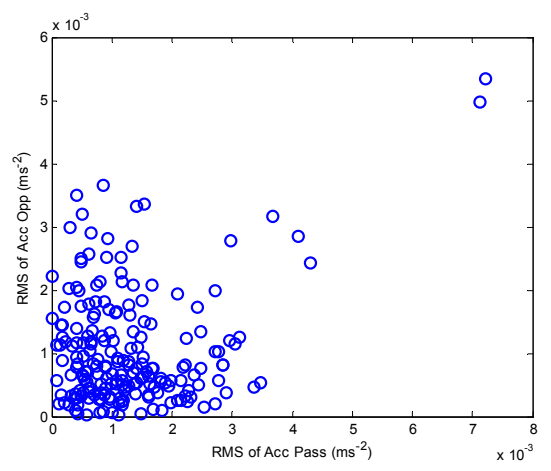

(b)

Figure 7. Cross-correlation between the passage and opposite way responses for $360 \mathrm{~km} / \mathrm{h}$. (a) cross-correlation maximum acceleration; (b) cross-correlation roote mean square (RMS) acceleration. 
In this case, the fitting equation is used to predict the opposite way measurements for the 400 and $406 \mathrm{~km} / \mathrm{h}$, as shown in Figure 8 . The correlation coefficient of the measured maximum values and predicted values with 400 and $406 \mathrm{~km} / \mathrm{h}$ is 0.999 and 0.998 for opposite accelerations, respectively. The results indicate that good cross-correlation exists between the maximum values of the opposite way at the two train speeds. Herein, the control chart can be used to monitor the changes in the vertical accelerations caused by deterioration of the vibration behavior. Firstly, the condition index $e$ ( $e=$ Max (measurements) - Max (prediction)) for early warning of abnormal vibration behavior is defined as the difference between the measured and predicted maximum values of the accelerations in the opposite way. Then, a mean value control chart is employed to monitor the time series of $e$ with regard to the opposite accelerations. For online monitoring, the controlling parameter is chosen so that, when the structural vibration is in good condition, all observation samples fall between the control limits. When the new measurement is made, the structural abnormal vibration condition can be detected if an unusual number of samples fall beyond the control limits. In this study, the control condition is assumed with $290 \mathrm{~km} / \mathrm{h}$ found within 0.025 to $-0.03 \mathrm{~m} / \mathrm{s}^{2}$. The calculated condition index for the 400 and $406 \mathrm{~km} / \mathrm{h}$ is between 0.0043 and $-0.028 \mathrm{~m} / \mathrm{s}^{2}$. Hence, a long-term monitoring of the maximum values of the opposite accelerations can help in the early-warning of the vibration behavior deterioration. These results are identical with the Ding et al. $[3,17]$ conclusions.

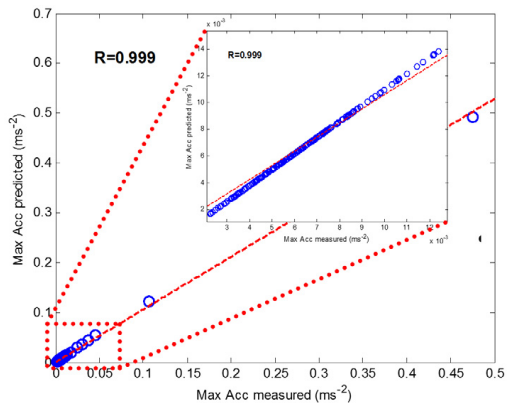

(a)

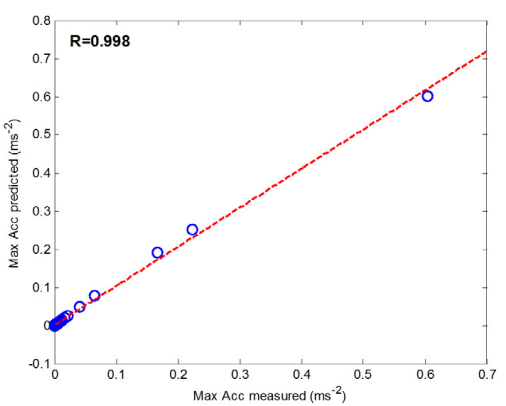

(b)

Figure 8. Predicting the effect of cross-correlation between maximum values of accelerations by using quadratic polynomials. (a) $400 \mathrm{~km} / \mathrm{h}$; (b) $406 \mathrm{~km} / \mathrm{h}$.

\subsection{Evaluation of the Bridge Girders' Train Responses}

The measured vertical strain histories of the monitoring points of the passage way for the train speeds 290 and $406 \mathrm{~km} / \mathrm{h}$ are presented in Figure 9a,b. The vertical strain of the mid-span point of passage and opposite ways for different train speeds are compared in Figure $9 \mathrm{c}, \mathrm{d}$. As the train speeds increase to $290,360,400$ and $406 \mathrm{~km} / \mathrm{h}$, the strain responses $(d t)$ decrease to $2.1,1.93,1.64$ and $1.61 \mathrm{~s}$, respectively. This shows that the time of static strain responses decreases by $23.33 \%$ when the speed changes from 290 and $406 \mathrm{~km} / \mathrm{h}$. In addition, the maximum strain response in the passage and opposite ways occurred at a speed of $290 \mathrm{~km} / \mathrm{h}$. The results as such show that the static and dynamic behavior of the bridge is higher with low train speeds. In addition, the strain measurements of the bridge points are highly correlated (0.95) with each speed change. This means that the strain measurement of the mid span point can be used to detect the performance of the whole bridge. This situation will decrease the cost of the monitoring system due to the use of one monitoring point only. The high correlation (0.99) of strain response for the passage and opposite ways occurred at 400 and $406 \mathrm{~km} / \mathrm{h}$. It means that the strain response of the two speeds is approximately equal in the static response. However, to show clearly the relationship between dynamic and static response of the bridge, the dynamic increment factor should be calculated and analyzed. The Savitzky-Golay finite impulse response(FIR) smoothing filter is applied to detect the static strain of the bridge. The first polynomial order with 101 frame size is utilized in this study. Figure 10a shows the strain measurements and filter data of the mid span of 
passage direction with a train speed of $406 \mathrm{~km} / \mathrm{h}$. Therefore, the dynamic increment factor (DF) can be calculated as follows [22,23]:

$$
\mathrm{DF}=1+\left(\frac{\mathrm{A}_{\mathrm{dyn}}}{\mathrm{A}_{\mathrm{stc}}}\right)
$$

where $A_{d y n}$ and $A_{\text {stc }}$ are the maximum absolute of dynamic and static amplitude of the strain, as shown in Figure 10a. The dynamic factors of passage $(\mathrm{P})$ and opposite $(\mathrm{O})$ directions for the monitored points are illustrated in Figure 10b.

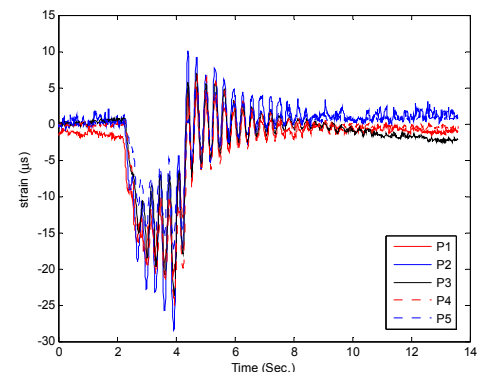

(a)

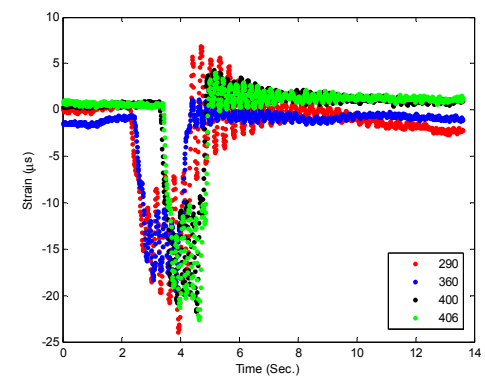

(c)

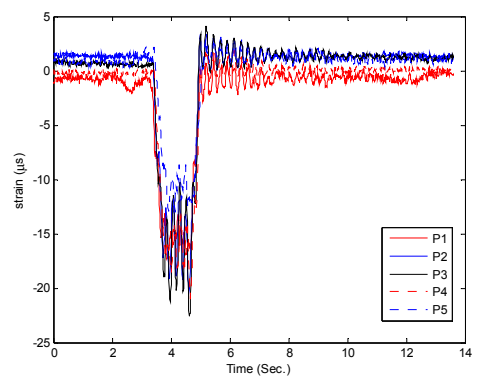

(b)

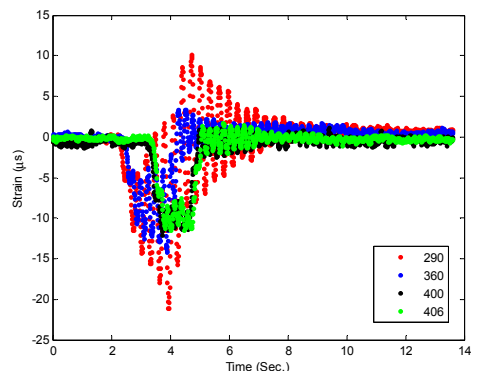

(d)

Figure 9. Strain measurements of the main girder induced by high-speed train. (a) passing response points for $290 \mathrm{~km} / \mathrm{h}$; (b) passing response points for $406 \mathrm{~km} / \mathrm{h}$; (c) passage response mid span points; (d) opposite response mid span points.

The dynamic factor calculation shows that the DF of $290 \mathrm{~km} / \mathrm{h}$ train is higher than other train speeds at the passage and opposite directions. Furthermore, the DF of the opposite direction is higher than the passage direction with all train speeds except point (P3) with speeds of 400 and $406 \mathrm{~km} / \mathrm{h}$.

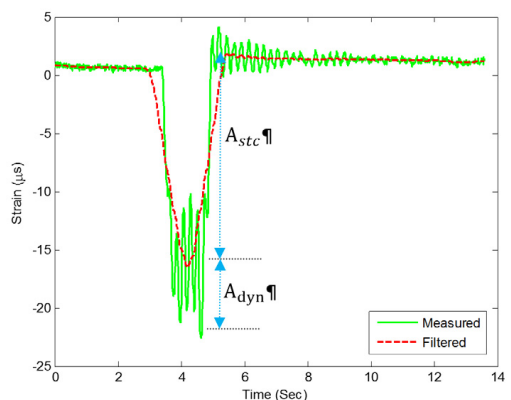

(a)

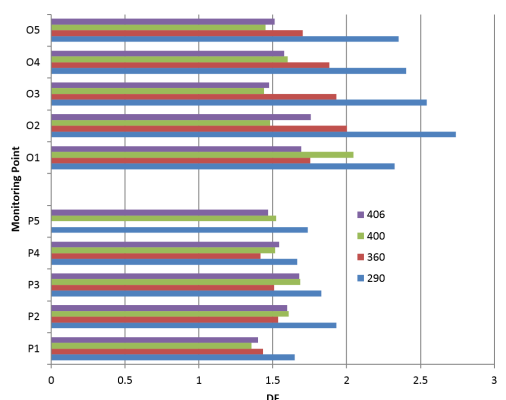

(b)

Figure 10. Measured static strain and dynamic factor of the strain. (a) measured and filtered static strain; (b) dynamic factor of the monitoring points.

From Figure 10b, it can be seen that the DFs for the development speeds are less than two. It means that the dominant performance of the bridge is static with speeds of 360,400 and $406 \mathrm{~km} / \mathrm{h}$ at all 
monitoring points, while the dynamic performance occurred at the opposite monitoring direction with train speed $290 \mathrm{~km} / \mathrm{h}$ and point (O1) with train speed $400 \mathrm{~km} / \mathrm{h}$. These results indicate that the static behavior increases with increased train speeds. Therefore, the fatigue and frequency behavior should be studied to investigate the safety of the bridge under high train speed effect.

Herein, the cross-correlation evaluation is used to predict the dynamic behavior of strain contents. The same conditions used in the acceleration analysis are used in this part. Figure 11 presents the cross-correlation and the cubic fitting of the maximum dynamic of strain measurements. The relationship between the maximum dynamic of strain contents in the passage and opposite directions for the train speed of $360 \mathrm{~km} / \mathrm{h}$ is illustrated in Figure 11a. While Figure 11b shows the prediction of the opposite direction contents of the dynamic strain for $406 \mathrm{~km} / \mathrm{h}$, the statistical analysis of cubic and quadratic fitting shows that the correlation coefficient of quadratic is 0.90 , so the cubic fitting in this case is better to predict the dynamic behavior of the strain contents. The comparison between the results of acceleration and strain dynamic contents shows that the dynamic evaluation of acceleration is better and effective to assess the vibration of the bridge, but the strain dynamic contents can be used to decrease the monitoring cost.

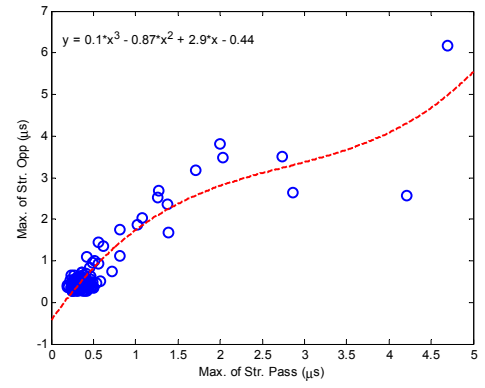

(a)

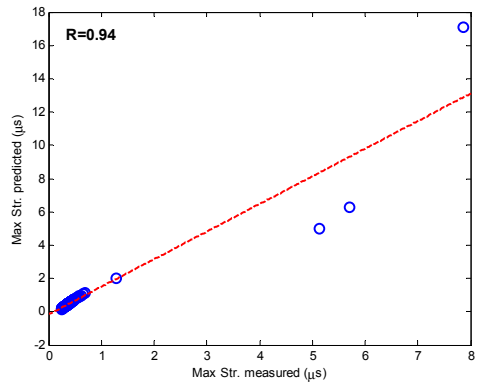

(b)

Figure 11. Cross-correlation and prediction of maximum strain dynamic. (a) cross-correlation maximum dynamic of strain; (b) predicting effect of cross-correlation.

To perform fatigue evaluation, a simplified rain-flow cycle counting algorithm was used first to process strain history data and the spectrum of stress matrix obtained by statistical analysis $[17,24]$. The spectra of stress matrix calculated using the strain history data with train speeds of 360 and $406 \mathrm{~km} / \mathrm{h}$ for the passage (left) and opposite (right) as shown in Figure 12, respectively. In addition, the maximum stress cycles are presented in Figure 12. It is observed that the maximum stress amplitude, obtained from strain history curves under two trains' effects for the passage and opposite directions, is smaller than $2.5 \mathrm{MPa}$. Therefore, only a small number of stress cycles occur at the higher stress range. Most cycles occur in the region of stress mean and amplitude from -0.5 to $0.5 \mathrm{MPa}$ and 0 to $0.5 \mathrm{MPa}$, respectively. Thus, the mean and amplitude values of the stress for the two trains in the two directions are equal.
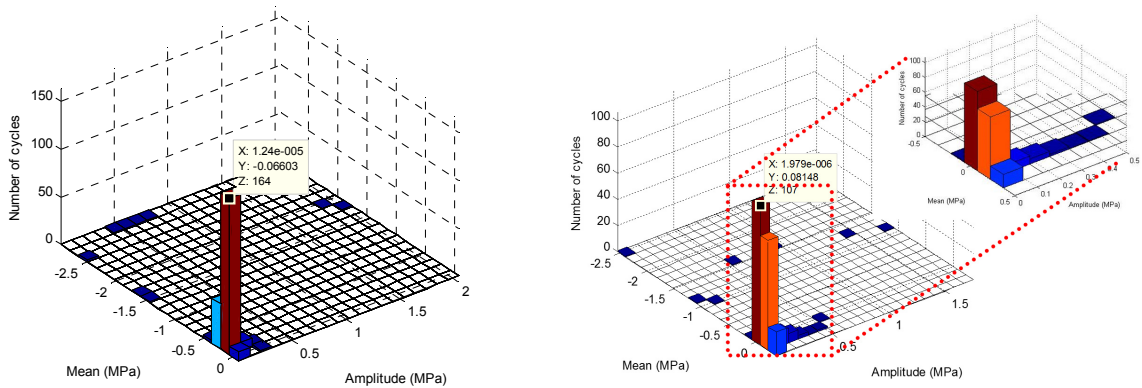

(a)

Figure 12. Cont. 

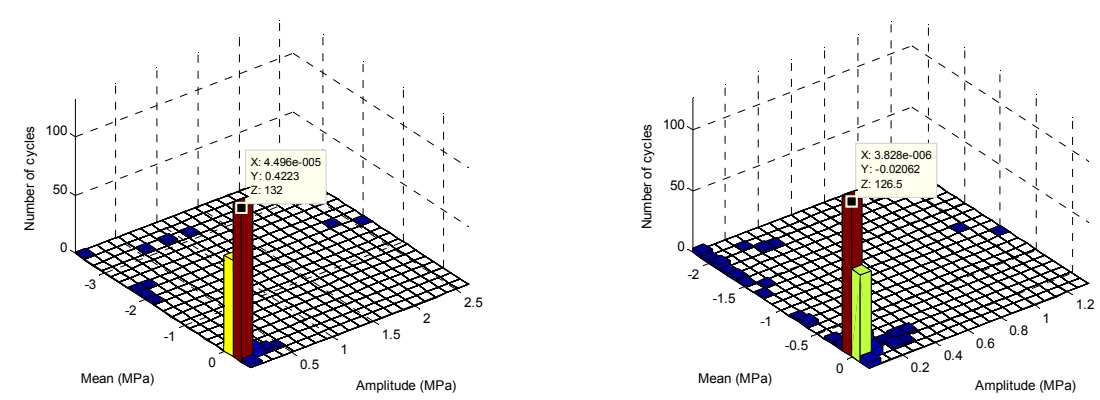

(b)

Figure 12. Rain-flow matrix of mid-span stress (a) $360 \mathrm{~km} / \mathrm{h}$; (b) $406 \mathrm{~km} / \mathrm{h}$.

The maximum number of stress cycles at $406 \mathrm{~km} / \mathrm{h}$ is smaller than that occurring at $360 \mathrm{~km} / \mathrm{h}$ in the two directions. The results show that the fatigue stress and number of cycles limit are $29 \mathrm{MPa}$ and $2 \times 10^{6}$, respectively [25], as recommended by Eurocode 3. The value of the equivalent stress amplitude and the number of cycles when the high-speed train passes through bridge is far less than this value for two trains. However, the fatigue behavior of the bridge deck satisfies the requirement of the infinite-fatigue-life design method.

\subsection{Acceleration-Strain Frequency Domain Evaluation}

The frequency contents of strain and acceleration measurements for the mid-span monitoring points in the passage and opposite directions are illustrated in Figure 13. The cross spectrum density function in Matlab (Version 7.6, MathWorks, Natics, MA, USA, 2008) is used to calculate the frequency contents.Based on the FEM [5] analysis, the band-pass filters in between 1 to $45 \mathrm{~Hz}$ with $101 \mathrm{hamming}$ window are used to filter the measured data to include the static and dynamic frequency contents of the bridge. From Figure 13, the frequency contents are 3.223, 3.906 Hz and 3.223, 4.199 Hz for 290 and $360 \mathrm{~km} / \mathrm{h}$ at the opposite and passage directions, respectively. In addition, the frequency contents equal $(4.297 \mathrm{~Hz})$ for the 400 and $406 \mathrm{~km} / \mathrm{h}$ at the two directions. From the comparison of the FEM frequency and real data, it is observed that the first dynamic mode changes increased with increasing the trains' speeds. The changes of passage frequency from the first bending FEM frequency mode are $18.5 \%, 24.2 \%, 25.8 \%$ for the speeds 290,360 and $406 \mathrm{~km} / \mathrm{h}$, respectively. The strain frequencies contents at the two directions with the effect of all trains' speeds are similar. In addition, the static frequency contents are clearly shown with strain measurements only. The low frequencies are $0.781,0.977,1.172$, $1.172 \mathrm{~Hz}$ and $0.879,1.074,1.172,1.172 \mathrm{~Hz}$ of the opposite and passage directions for the 290, 360, 400, $406 \mathrm{~km} / \mathrm{h}$ train speeds, respectively. It means that the strain measurements are enough to estimate the static and dynamic behavior in frequency domain. Moreover, from the comparison between the first mode contents of the measurements and the FEM calculations, it can be concluded that the bridge is safe under its current dynamic behavior with the development speeds of trains.

The Matlab Spectrogram toolbox is used to extract the three dimensional time-frequency maps for the passage train at the mid-span point of the bridge at speeds 290 and $406 \mathrm{~km} / \mathrm{h}$, as shown in Figure 14. The results show that the power spectrum density (PSD) at $290 \mathrm{~km} / \mathrm{h}$ speed is lower than the PSD amplitude at $406 \mathrm{~km} / \mathrm{h}$. The PSD frequency responses' amplitude differences between trains passage and departure (load and unload) show small values at $406 \mathrm{~km} / \mathrm{h}$. Therefore, it is concluded that the dynamic behavior of the bridge at train speeds of $406 \mathrm{~km} / \mathrm{h}$ is greater than the $290 \mathrm{~km} / \mathrm{h}$. However, it is concluded that the bridge is safe at a speed of $406 \mathrm{~km} / \mathrm{h}$, but it should be continuously monitored if trains speeds are increased above this value. Moreover, the increase of PSD with train speeds indicates that the simple beam girders of steel bridges are very sensitive to train induced vibrations, and, therefore, may be not suitable for an increase in the speed of train traffic. 


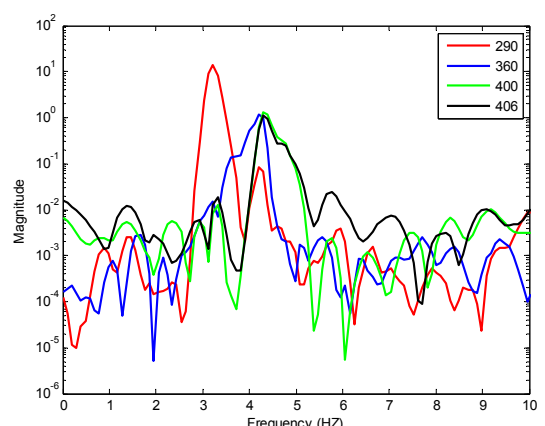

(a)

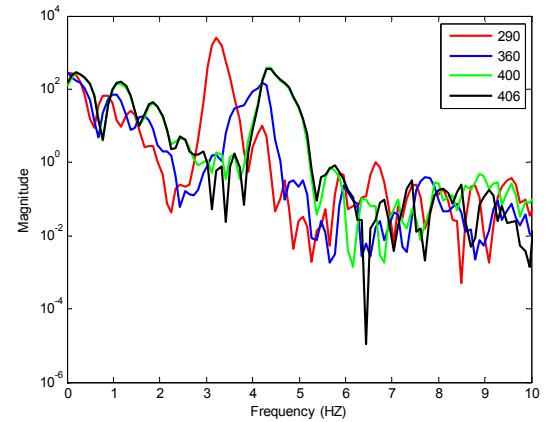

(c)

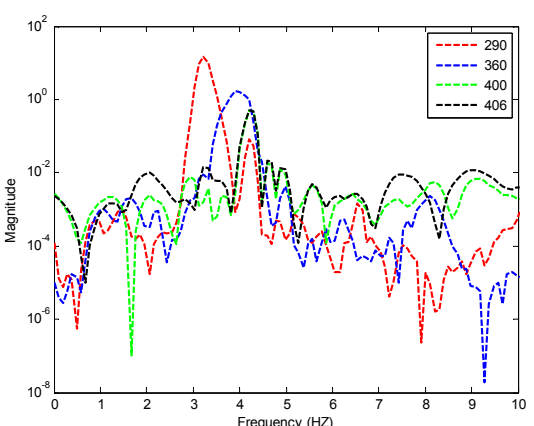

(b)

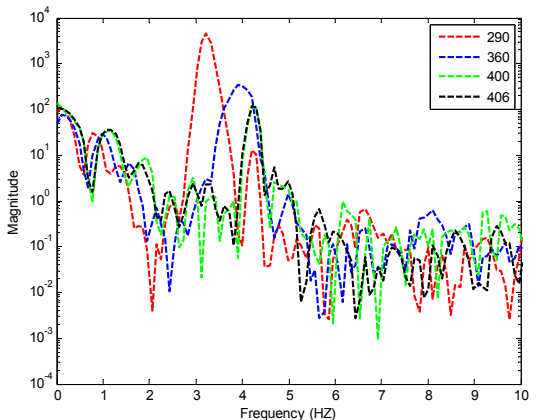

(d)

Figure 13. Acceleration and strain frequency contents. (a) passage-acceleration; (b) opposite-acceleration; (c) passage-strain; (d) opposite-strain.

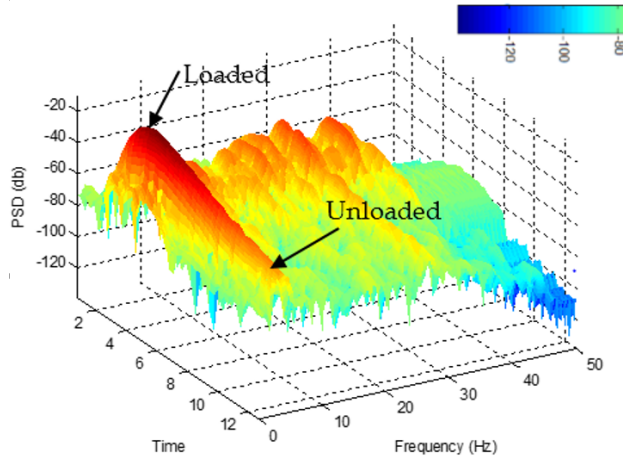

(a)

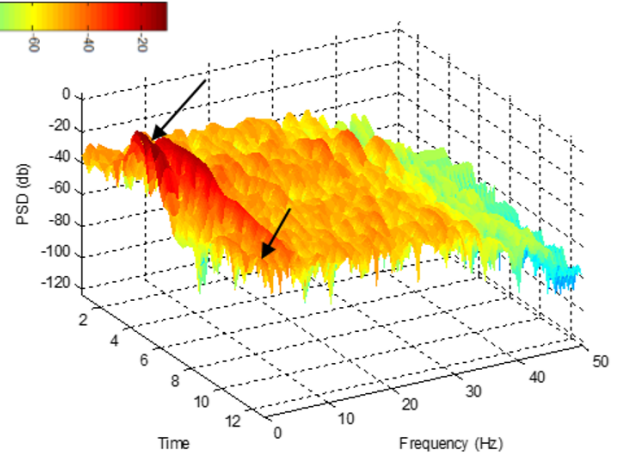

(b)

Figure 14. Time-frequency acceleration measurements for the trains speeds (a) $290 \mathrm{~km} / \mathrm{h}$ and (b) $406 \mathrm{~km} / \mathrm{h}$.

\section{Summary and Conclusions}

This paper aims to evaluate the measurements of a structural health monitoring system of the Kaya railway bridge in Korea with high-speed trains. A non-destructive monitoring system using accelerometers and strain sensors is designed to monitor the performance of the bridge under new development train speeds of 400 and $406 \mathrm{~km} / \mathrm{h}$. The static and dynamic behavior of the bridge are analyzed and discussed. Accordingly, the following remarks and conclusions are drawn:

- The mathematical correlation models describing the overall structural behavior of the bridge can be obtained with the support of the health monitoring system.

- The torsional response shows a higher effect than the vibration response on the bridge deck.

- The effective torsion test should be assessed at the end points of the bridge. 
- The mean value control chart for the acceleration and strain can be applied for bridge monitoring and for the early warning of any abnormal behavior.

- The dynamic factor calculation shows that the static behavior increases with train speed developments.

- The statistical analysis of cubic and quadratic fits shows that the cubic fitting in monitoring strain is better to predict the dynamic behavior of the strain contents.

- The comparison between the results of acceleration and strain dynamic contents shows that the dynamic evaluation of acceleration is better and effective to assess the vibration of the bridge, but the strain dynamic contents can be used to decrease the monitoring cost.

- The fatigue performance of the bridge deck satisfies the requirement of infinite-fatigue-life design method, and the highest cycles occur in a close region of stress mean and amplitude. Therefore, the bridge-deck fatigue is safe under current trains' speeds.

- The frequency calculation of the acceleration and strain measurements shows that the strain measurements are enough to estimate the static and dynamic behaviorin frequency domain.

- Comparing the first mode contents of the measurements and the FEM calculations shows that the dynamic behavior of the bridge is safe with development speeds of trains.

- The increase of PSD with train speeds indicates that the simple beam girders of steel bridges are very sensitive to train induced vibrations, and, therefore, may be not suitable for increased speed of train traffic.

- Based on the vibration, torsion, fatigue and frequency contents of the bridge, it is concluded that the bridge is safe under the development speed with a recommendation not to increase the train speed because the torsion performance is critical at $406 \mathrm{~km} / \mathrm{h}$ at the entrance and exit monitoring points.

Acknowledgments: This research was supported by the Basic Science Research Program through the National Research Foundation of Korea (NRF) funded by the Ministry of Science, information and communication technology (ICT), and Future Planning (Grant No. 2013R1A2A2A01068174).

Author Contributions: The authors have contributed equally to this work.

Conflicts of Interest: The authors declare no conflict of interest.

\section{References}

1. Lee, J.; Kim, S.; Kwark, J.; Lee, P.; Yoon, T. Dynamic characteristics of high-speed railway steel bridges. Trans. Korean Soc. Noise Vib. Eng. 2007, 17, 632-637. (In Korean).

2. Xia, H.; de Roeck, G.; Zhang, N.; Maeck, J. Experimental analysis of a high-speed railway bridge under Thalys trains. J. Sound Vib. 2003, 268, 103-113. [CrossRef]

3. Ding, Y.; Sun, P.; Wang, G.; Song, Y.; Wu, L.; Yue, Q.; Li, A. Early-Warning Method of Train Running Safety of a High-Speed Railway Bridge Based on Transverse Vibration Monitoring. Shock Vib. 2015, 2015, 518689. [CrossRef]

4. Al Shaer, A.; Duhamel, D.; Sab, K.; Foret, G.; Schmitt, L. Experimental settlement and dynamic behavior of a portion of ballasted railway track under high speed trains. J. Sound Vib. 2008, 316, 211-233. [CrossRef]

5. Kim, E.; Park, J.; Sim, S. Dynamic Behavior of Composite Steel Girder Bridge Exceeding Train. J. Korea Acad. Ind.Cooperation Soc. 2013. (in Korean). [CrossRef]

6. Liu, K.; Reynders, E.; de Roeck, G.; Lombaert, G. Experimental and numerical analysis of a composite bridge for high-speed trains. J. Sound Vib. 2009, 320, 201-220. [CrossRef]

7. Majka, M.; Hartnett, M.; Bien, J.; Zwolski, J. Experimental and numerical dynamic analysis and assessment of a railway bridge subjected to moving trains. In Proceedings of the 3rd International Conference on Bridge Maintenance, Safety and Management-Bridge Maintenance, Safety, Management, Life-Cycle Performance and Cost, Porto, Portugal, 16-19 July 2006; pp. 713-714.

8. Koh, H.M.; Kim, S.; Choo, J.F. Recent Development of Bridge Health Monitoring System in Korea. In Sensing Issues in Civil Structural Health Monitoring; Springer: Heidelberg, Germany, 2005; pp. 33-42. 
9. Koh, H.-M.; Lee, H.-S.; Kim, S.; Choo, J.F. Monitoring of Bridges in Korea. In Encyclopedia of Structural Health Monitoring; John Wiley \& Sons: Chichester, England, 2009.

10. Arangio, S.; Bontempi, F. Structural health monitoring of a cable-stayed bridge with Bayesian neural networks. Struct. Infrastruct. Eng. 2015, 11, 575-587. [CrossRef]

11. Zhang, Q. Statistical damage identification for bridges using ambient vibration data. Comput. Struct. 2007, 85, 476-485. [CrossRef]

12. Zhan, J.; Xia, H.; Chen, S.; de Roeck, G. Structural damage identification for railway bridges based on train-induced bridge responses and sensitivity analysis. J. Sound Vib. 2011, 330, 757-770. [CrossRef]

13. Yam, L.; Yan, Y.; Jiang, J. Vibration-based damage detection for composite structures using wavelet transform and neural network identification. Compos. Struct. 2003, 60, 403-412. [CrossRef]

14. Sartor, R.; Culmo, M.; DeWolf, J. Short-Term Strain Monitoring of Bridge Structures. J. Bridg. Eng. 1999, 4, 157-164. [CrossRef]

15. Xia, H.; Zhang, N.; de Roeck, G. Dynamic analysis of high speed railway bridge under articulated trains. Comput. Struct. 2003, 81, 2467-2478. [CrossRef]

16. Li, Z.; Chan, T.; Zheng, R. Statistical analysis of online strain response and its application in fatigue assessment of a long-span steel bridge. Eng. Struct. 2003, 25, 1731-1741. [CrossRef]

17. Ding, Y.; Wang, G.; Sun, P.; Wu, L.; Yue, Q. Long-term structural health monitoring system for a high-speed railway bridge structure. Sci. World J. 2015, 2015, 250562. [CrossRef] [PubMed]

18. Kaloop, M. Bridge safety monitoring based-GPS technique: case study Zhujiang Huangpu Bridge. Smart Struct. Syst. 2012, 9, 473-487. [CrossRef]

19. Kaloop, M.; Hu, J. Stayed-Cable Bridge Damage Detection and Localization Based on Accelerometer Health Monitoring Measurements. Shock Vib. 2015, 2015, 102680. [CrossRef]

20. Elnabwy, M.; Kaloop, M.; Elbeltagi, E. Talkha steel highway bridge monitoring and movement identification using RTK-GPS technique. Meas. J. Int. Meas. Confed. 2013, 46, 4282-4292. [CrossRef]

21. Lorieux, L. Analysis of Train-Induced Vibrations on a Single-Span Composite Bridge. Master Thesis, The Royal Institute of Technology (KTH), Stockholm, Sweden, 2008.

22. Gao, Q.; Wang, Z.; Jia, H.; Liu, C.; Li, J.; Guo, B.; Zhong, J. Dynamic Responses of Continuous Girder Bridges with Uniform Cross-Section under Moving Vehicular Loads. Math. Probl. Eng. 2015, 2015, 951502. [CrossRef]

23. Maljaars, J.; Waarts, P.; Leenderts, J.; Hoogvelt, R. Dynamic increment factor in modular expansion joints of bridges under heavy traffic loading. In Proceedings of the 7th International Symposium on Heavy Vehicles Weights and Dimensions, Delfet, The Netherland, 16-20 June 2002; pp. 289-302.

24. Li, S.; Li, H.; Liu, Y.; Lan, C.; Zhou, W.; Ou, J. SMC structural health monitoring benchmark problem using monitored data from an actual cable-stayed bridge. Struct. Control Health Monit. 2014, 21, 156-172. [CrossRef]

25. European Committee for Standardization. Eurocode 3: Design of Steel Structures, Part 1-9: Fatigue; BS EN 1993-1-9:2005; European Committee for Standardization: Brussels, Belgium, 2005.

(C) 2016 by the authors; licensee MDPI, Basel, Switzerland. This article is an open access article distributed under the terms and conditions of the Creative Commons by Attribution (CC-BY) license (http://creativecommons.org/licenses/by/4.0/). 